\title{
Multi-factor productivity: estimates for 1970 to 2009
}

Jean Acheson

Office for National Statistics

\section{Summary}

This article presents multi-factor productivity (MFP) estimates using experimental measures of quality adjusted labour inputs and capital services. Using a growth accounting framework, output growth can be split into the relative contributions of labour and capital inputs, and a residual component called MFP. MFP is also described in the literature as 'disembodied technical change', the 'Solow residual' or total factor productivity. This approach complements traditional measures of productivity, which focus only on one input - labour - and take account only of the volume of labour and not changes in the composition of labour over time. The most recent data highlights how MFP has declined during the recession at both the whole economy and industry level. The article also backcasts the series to 1970 using the EU KLEMS dataset to create a longer run picture of MFP.

\section{Introduction}

Using a growth accounting framework, growth in output can be decomposed into contributions from growth in labour inputs (in terms of both its quantity and composition) and from growth in capital services. The residual output growth that cannot be accounted for by growth in labour and capital inputs is hence an estimate of multi-factor productivity (MFP). This term is sometimes referred to as the 'Solow residual' or total factor productivity (TFP). Whilst conceptually this MFP residual can be thought of as capturing technological progress, in practice it may also capture a number of other effects. These may be effects such as an improvement in the quality of the labour force not captured by the quality adjusted labour inputs; changes in management techniques or business processes; or returns from expenditures that are not currently treated as capital formation within the national accounts framework, such as research and development. Some element of MFP will also reflect adjustment costs, economies of scale and measurement error in inputs and outputs.

A distinctive feature of this analysis is its utilisation of estimates of quality adjusted labour inputs, known as QALI. This allows for the contribution of labour inputs to be attributed to both an increase in the volume of labour, in terms of actual hours worked, and an increase in the quality of 
the labour, in terms of the skill composition of the work force. The analysis also utilises estimates of volume indices of capital services, referred to as VICS. The VICS measure is analogous to QALI in capturing compositional changes in capital inputs more fully than alternative measures of capital input, such as changes in net capital stocks. For the most recent analysis of QALI, see Acheson (2011). For more on VICS, see Appleton and Wallis (2011).

\section{Growth accounting}

The growth accounting framework, first developed by Solow (1957), attempts to measure the contribution of different factor inputs to economic growth. Any output growth not explained by growth in these factor inputs is known as multi-factor productivity growth. The specific methodology adopted in this analysis uses gross value added (GVA) as an output measure and VICS and QALI as its factor inputs. This approach to growth accounting is relatively undemanding in terms of data requirements ${ }^{1}$. The data necessary to produce quality adjusted labour inputs and capital services can readily be found in the National Accounts and Labour Force Survey.

MFP estimates are often interpreted as measuring the effect of 'disembodied technical change' those advances in technology not embodied in capital. Examples of disembodied technical change include increased knowledge due to R\&D, improved management techniques, changes in organisational structure or more efficient utilisation of ICT. It is important to note that improvements in the quality of capital are examples of 'embodied technical change'. In principle, such quality changes are captured in the measurement of capital services (directly analogous to the measurement of labour quality changes) and are not included in MFP. MFP is linked, therefore, not to an increase in the quantity or quality of measured factor inputs but rather to how they are employed.

\section{Methodology}

Following Solow (1957), the production function is assumed to take the following form:

$$
Y=A(t) f(K, L)
$$

Where $A(t)$ represents disembodied technical change, $K$ denotes the volume of capital inputs (measured by VICS), $L$ denotes the volume of labour inputs (measured by QALI) and $Y$ denotes the volume of output, measured by gross value added. This production function embodies the assumption of neutral technical change, that is, the disembodied technological shift factor, $A(t)$, leaves the marginal rates of technical substitution of the labour and capital inputs unchanged. It is additionally assumed that factors are paid their marginal products. Given that all factor inputs are classified as either labour or capital, this implies constant returns to scale in the production function. 
Taking the total differential with respect to time and dividing by output gives the proportionate growth in output (where dots denote time derivatives):

$$
\frac{\dot{Y}}{Y}=A \frac{\partial f}{\partial K} \frac{\dot{K}}{Y}+A \frac{\partial f}{\partial L} \frac{\dot{L}}{Y}+\frac{\dot{A}}{A}
$$

If the relative income shares of capital and labour are denoted as follows, $w_{k}=\frac{\partial Y}{\partial K} \frac{K}{Y}$ and $w_{l}=\frac{\partial Y}{\partial L} \frac{L}{Y}$ then (noting that $\partial Y / \partial K=A \partial f / \partial K$ and so on) growth in output can be expressed as an income share weighted sum of factor input growth and growth in disembodied technical change:

$$
\frac{\dot{Y}}{Y}=w_{k} \frac{\dot{K}}{K}+w_{l} \frac{\dot{L}}{L}+\frac{\dot{A}}{A}
$$

Here, the assumption of constant returns to scale implies that the capital share of income is equal to one minus the labour share of income, that is, $w_{k}=\left(1-w_{l}\right)$. In discrete time, this can be rearranged and approximated as:

$$
\Delta \ln Y(t)=\bar{s}_{l}(t) \Delta \ln L(t)+\left[1-\bar{s}_{l}(t)\right] \Delta \ln K(t)+\Delta \ln A(t)
$$

Where $\bar{s}_{l}$ represents the average labour share of total income between the current and previous period. This states that the growth in log GVA is equal to growth in log labour input weighted by the labour income share plus growth in log capital input weighted by the capital income share plus growth of the disembodied technical change (MFP) parameter. This shows how an estimate of MFP can be recovered as a residual.

This framework can be adapted in order to obtain a decomposition of growth that includes the contribution of labour composition. Letting $H$ denote unadjusted labour inputs (measured by hours), then:

$$
\frac{\dot{Y}}{Y}-\frac{\dot{H}}{H}=w_{k} \frac{\dot{K}}{K}+w_{l} \frac{\dot{L}}{L}-\frac{\dot{H}}{H}+\frac{\dot{A}}{A}
$$

which, after some re-arrangement, can be simplified to:

$$
\frac{\dot{Y}}{Y}-\frac{\dot{H}}{H}=w_{k}\left(\frac{\dot{K}}{K}-\frac{\dot{H}}{H}\right)+w_{l}\left(\frac{\dot{L}}{L}-\frac{\dot{H}}{H}\right)+\frac{\dot{A}}{A}
$$

In discrete time this equation can be further re-arranged and approximated as follows:

$$
\Delta \ln \left[\frac{Y(t)}{H(t)}\right]=\bar{s}_{l}(t)[\Delta \ln L(t)-\Delta \ln H(t)]+\left(1-\bar{s}_{l}(t)\right)[\Delta \ln K(t)-\Delta \ln H(t)]+\Delta \ln A(t)
$$


This states that growth in log GVA per hour of labour input (that is, labour productivity as conventionally measured, for example in the ONS quarterly Productivity Statistical Bulletin ${ }^{2}$ ) can be decomposed into the contributions of weighted labour composition (the difference between the growth of quality adjusted and unadjusted labour inputs), capital deepening (defined as the weighted growth in capital inputs per hour worked) and MFP growth. The quality adjustment measure of labour input explicitly accounts for the heterogeneity of labour inputs by adjusting for changes in labour supply as reflected by education, gender and industry of employment. This is in contrast to a standard aggregation of labour which treats each hour of labour input as homogeneous.

\section{Source data}

The labour input measure, QALI, is mainly derived from quarterly Labour Force Survey (LFS) data. This allows information on the educational, industrial, age and gender composition of the labour inputs to be gained. Making the assumption that factors are paid their marginal products, the hours worked by each compositional category are weighted by their share in total labour income. This quality adjustment procedure captures, at least partially, the contribution to output growth of changes in the skill level of the workforce rather than attributing this contribution to MFP growth. For more information on QALI and the latest estimates see Acheson (2011). Unadjusted hours consistent with QALI are also used as an input to the MFP framework.

The capital input measure used in this MFP analysis is the volume index of capital services (VICS). This measures the flow of capital services to the production process in each period. Capital services differ from National Accounts capital stock measures as they weight together the growth in the net stock of assets using rental rather than purchase prices. This is conceptually more appropriate for use in growth accounting analysis since, under the assumption that factors receive their marginal products, rental prices better reflect the marginal productivity of a given capital asset. Capital services estimates also provide a greater level of asset detail than the National Accounts net capital stock measures. The separate treatment of the short-lived ICT assets of computer hardware, purchased software and own-account software is a particular advantage of the VICS measure. Further information about VICS and the latest estimates can be found in Appleton and Wallis (2011).

The output measure used in this MFP analysis is a chained volume index of GVA at basic prices, consistent with Blue Book 2010. The labour share of total income is calculated as the sum of Compensation of Employees ( $\mathrm{CoE}$ ) from the National Accounts and the labour compensation of the self employed as a proportion of total GVA. There is no National Accounts series for the labour income of the self-employed. Instead the National Accounts 'mixed income' series includes the returns to both capital and labour of the self-employed. In order to approximate the labour return component of mixed income, the ratio of compensation of employees to the sum of compensation of employees and gross operating surplus in the employed sector is applied to mixed income. The capital share in total income is simply one minus the labour share, due to our assumption that all factor inputs are either capital or labour. 


\section{Results}

This section presents growth accounting results over the period 1995 to 2009 for the whole economy, ten industry groups (which are detailed in Table 1) and for the market sector ${ }^{3}$. Due to the volatility of year on year MFP growth, the results are mainly presented as averages over the periods. The backcasting of the series to 1970 relies on data from the EU KLEMS project ${ }^{4}$. It was not possible to backcast the market sector as EU KLEMS uses a different definition to ONS.

\section{Table $1 \quad$ Industry descriptions}

\begin{tabular}{ll}
\hline Industry* & Industry description \\
\hline ABCE & Agriculture, hunting and forestry; fishing; mining and quarrying; utilities \\
D & Manufacturing \\
F & Construction \\
G & Wholesale and retail trade \\
H & Hotels and restaurants \\
I & Transport, storage and communications \\
J & Financial intermediation \\
K & Real estate, renting and business activities \\
LMN & Public administration and defence; education; health and social work \\
OPQ & Other social and personal services \\
\hline
\end{tabular}

* Standard Industrial Classification (2003)

Figure 1 decomposes the average growth in output from 1995 to 2009 into the contributions from capital and labour input growth, MFP growth and growth in the quality of labour, known as labour composition. At the whole economy level, average annual MFP growth is estimated to be 0.3 per cent, compared with average output growth of 2.2 per cent per annum over the period. The greatest contribution to growth came from capital inputs, which accounts for half of output growth. Growth in the quality of labour composition accounted for a more modest 0.4 per cent of growth per annum.

With an average annual growth rate of half a per cent between 1995 and 2009, MFP represented a fifth of market sector output growth. This more positive contribution of MFP to output growth relative to the whole economy is driven by negative MFP growth in LMN (public administration and defence and so on) and OPQ (social and personal services) which contain a significant amount of non-market output. These industries may not face the competitive pressures to utilise their factor inputs efficiently in the same way that market sector industries do. It is also possible that the measures of non-market sector output are not fully capturing changes in quality. Work is currently ongoing within ONS to improve these output measures ${ }^{5}$. 
Growth in market sector capital services was similar to that of the whole economy. However the contribution to growth due to labour composition was less than that of the whole economy, due to the strong labour composition effects of LMN and OPQ in particular, whose activities are mainly in the non-market sector.

\section{Figure 1 Decomposition of annual average output growth, 1995- 2009}

Percentage points

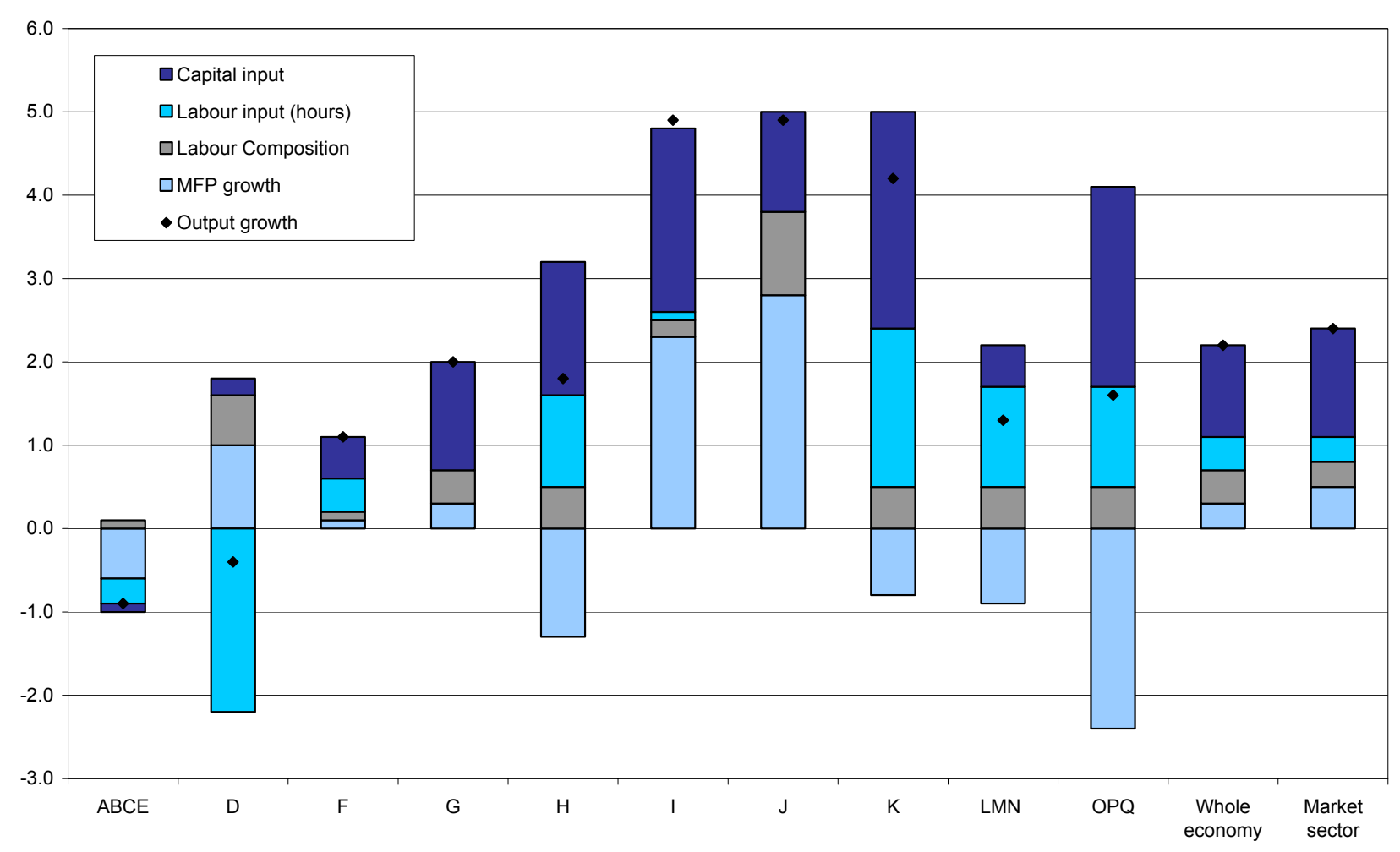

Source: Office for National Statistics

Turning to the industrial groupings, the strongest MFP growth over the period occurred in industry $\mathrm{J}$ (financial intermediation) with an annual average growth rate of 2.8 per cent. This accounts for over half of total output growth in this section, reflecting rapid technical progress in communications in particular. Strong MFP growth also occurred in sections D (manufacturing) and I (transport, storage and communication). Labour quality made a positive contribution to output growth in each of the ten industrial groups with $\mathrm{J}$ in particular benefiting from the increased utilisation of high skilled labour.

Notwithstanding rapid MFP growth in industries I and J, average annual MFP growth in the service sector as a whole (industries $G$ to $Q$ ), lagged behind that of the production sector (industries $A$ to F). A commonly cited explanation for the disparity in productivity between production and service activities is the Baumol Effect (Baumol, 1967). The theory behind the Baumol Effect is that the relative productivity underperformance of the services sector is due to its relative labour intensity. 
This makes it worse placed to benefit from productivity improvements arising from technological advances.

As discussed in the methodology section, a decomposition of labour productivity growth can be used to inform analysis of the drivers of growth in the headline productivity measures. Figure 2 decomposes labour productivity growth into the contributions from labour composition, MFP and the amount of capital per hour worked (known as capital deepening). The graph highlights divergence in labour productivity growth rates across industries and MFP is a clear driver of this.

Figure 2

Decomposition of annual average labour productivity, 1995 to 2009

Percentage points

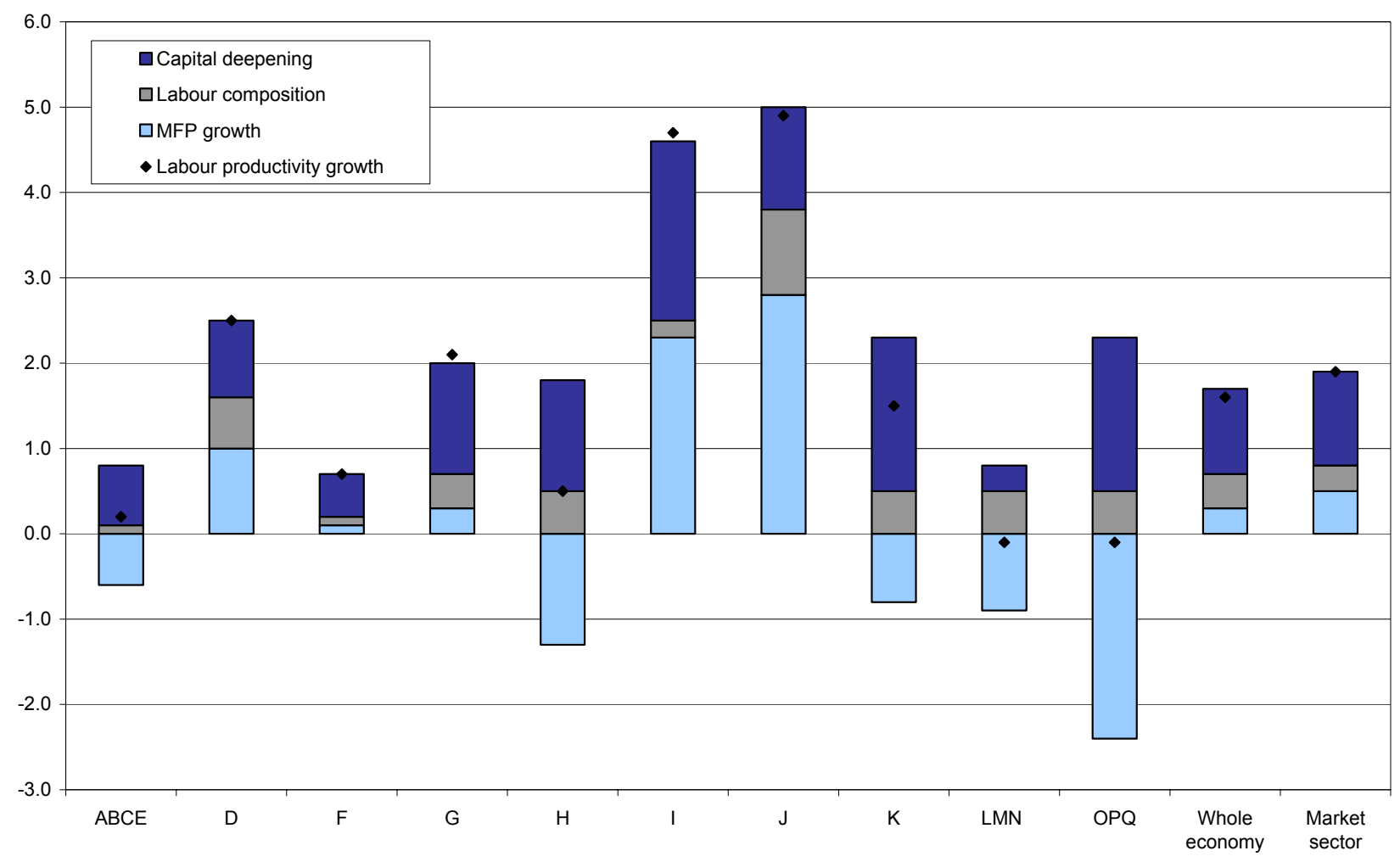

Source: Office for National Statistics

Over 1995 to 2009, capital deepening accounted for over 60 per cent of labour productivity growth at the more aggregated levels of the whole economy and the market sector. In fact a positive contribution from capital deepening occurred in each of the industrial groupings. The industries with the greatest contribution from capital deepening are those in the service sector. This partly reflects rapid growth in ICT investment over the period. The contribution of labour quality was generally much more modest, at both the whole economy and industrial levels, with the exception of $\mathrm{K}$ (real estate, renting and business activities) where it accounted for almost a third of labour productivity growth. 
Using the EU KLEMS dataset and other National Accounts and Labour Force Survey series, the MFP series for the whole economy and for the industrial groupings was backcast to 1970. Figure 3 takes the average growth rate for this period and decomposes it into its constituent parts ${ }^{6}$. At the whole economy level, capital input and MFP are the clear drivers of growth; there are significant differences across industries, however. MFP makes a positive contribution to growth in all the production industries, but its performance is mixed across the services. It is strongest in I while it has made a negative contribution to growth in $\mathrm{H}$ (hotels and restaurants) and LMN. Labour composition made the largest contribution to $\mathrm{OPQ}$, at almost a third of its average output growth over the period. The lack of MFP growth in $\mathrm{J}$ over this longer time period is in marked contrast to the strong positive contribution over the most recent period shown in Figure 1.

\section{Figure 3 Decomposition of annual average output growth, 1970- 2009}

Percentage points

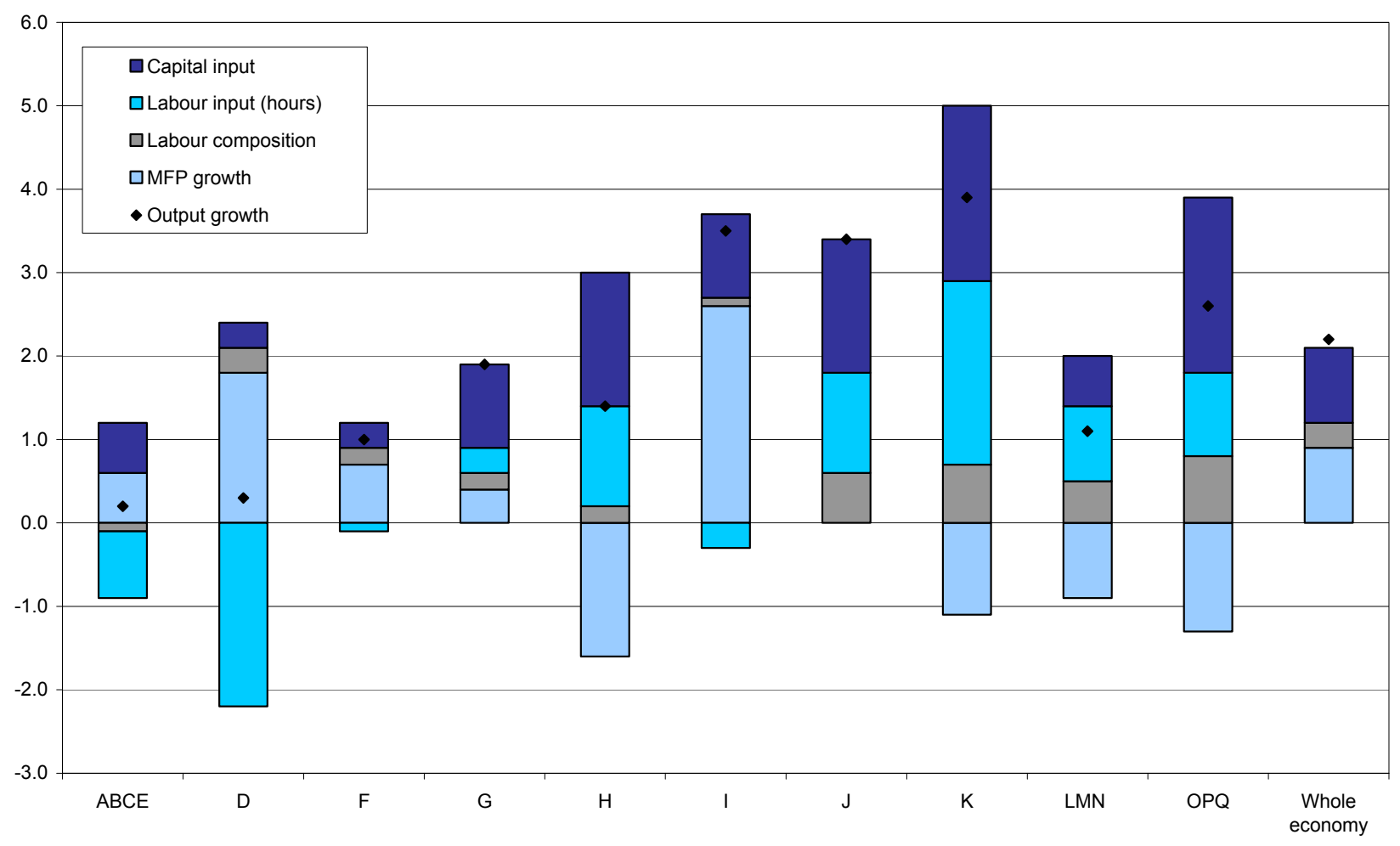

Source: Office for National Statistics

Figure 3 is useful for the long run perspective it gives and for its smoothing out of the economic cycles, but the most recent data is worth examining in closer detail. The time series of the breakdown for the whole economy over the past decade highlights the deterioration in output and MFP growth over the recession. In Figure 4, the 2009 growth rate in particular reveals a very different pattern to preceding years. 


\section{Figure 4 Decomposition of annual output growth for the whole economy, 2000-2009}

Percentage points

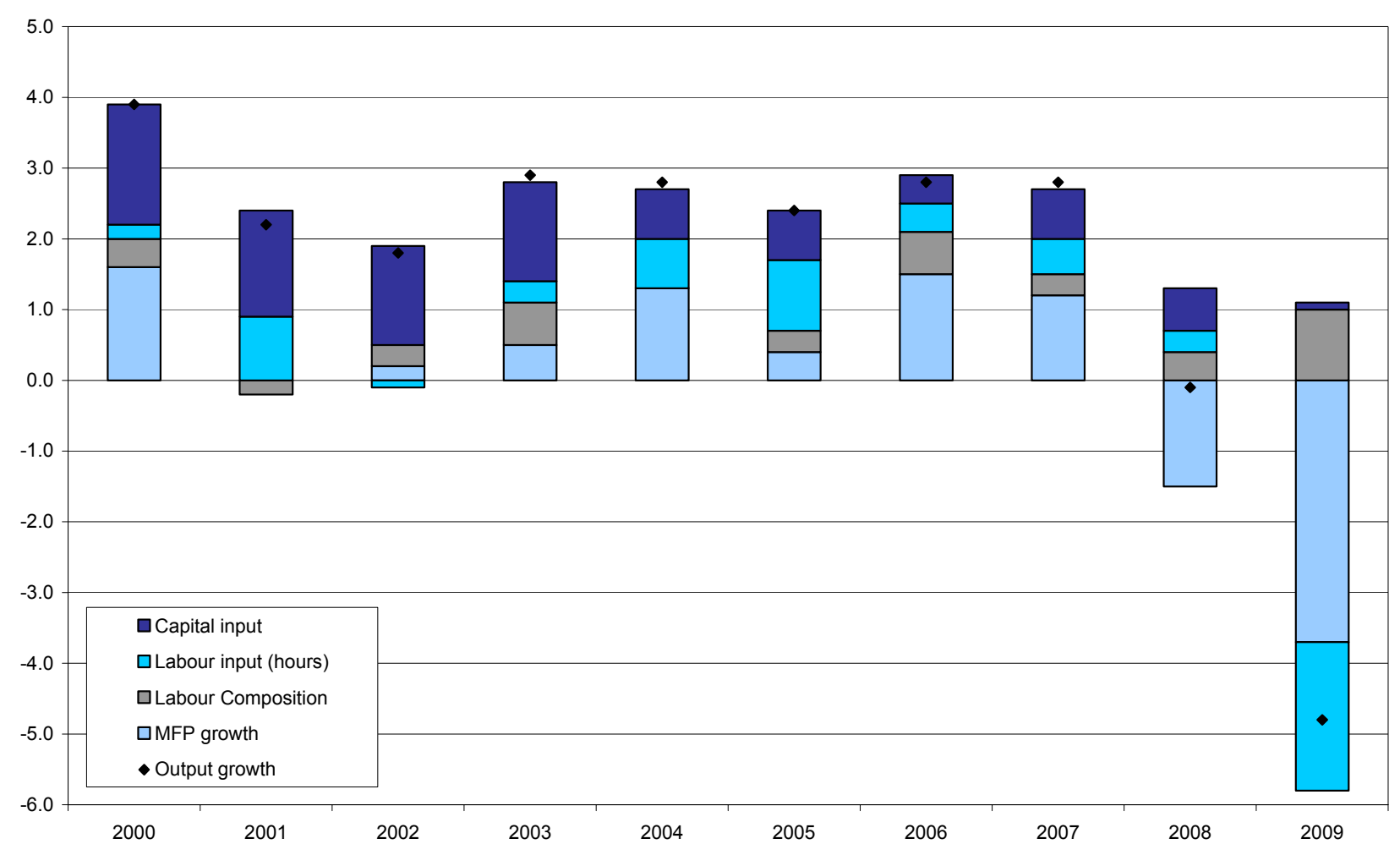

Source: Office for National Statistics

Although growth accounting is not an analysis of causation, the results in Figure 4 show that the contribution of MFP to growth is highly pro-cyclical: the stalling of output growth in 2008 entirely reflects the negative contribution of MFP. And while the volume of labour input fell in 2009, in growth accounting terms MFP accounted for a larger proportion of the decline in output. The fall in labour input is to be expected as labour shedding is common in economic downturns, but the strong positive contribution of labour composition in 2009 reveals that, on average, it was the lowest skilled workers who bore the brunt of the reduction in hours (see Acheson (2011) for further details).

If MFP is interpreted as the efficiency with which other factors are used, the 2009 result suggests the UK economy is not responding robustly to the economic decline as factor inputs are not being utilised to their full capacity. The fall in MFP in 2009 is also greater than its fall in the previous two recessions, although this result may be affected by the greater severity of the 2008/09 recession. The cyclical fall in efficiency could also be heightened by measurement error, for example it is difficult to measure the impact of capacity scrapping on capital services during a turning point in the economic cycle. 
A decomposition of labour productivity in 2009 similarly shows the poor performance of MFP across industries (Figure 5). This result reinforces the pro-cyclical nature of MFP. However, as stated previously, the yearly estimates of MFP are quite volatile and Figure 5 should mainly be used as a tool to highlight the divergences in productivity across industries.

\section{Figure 5 Decomposition of labour productivity growth, 2009}

Percentage points

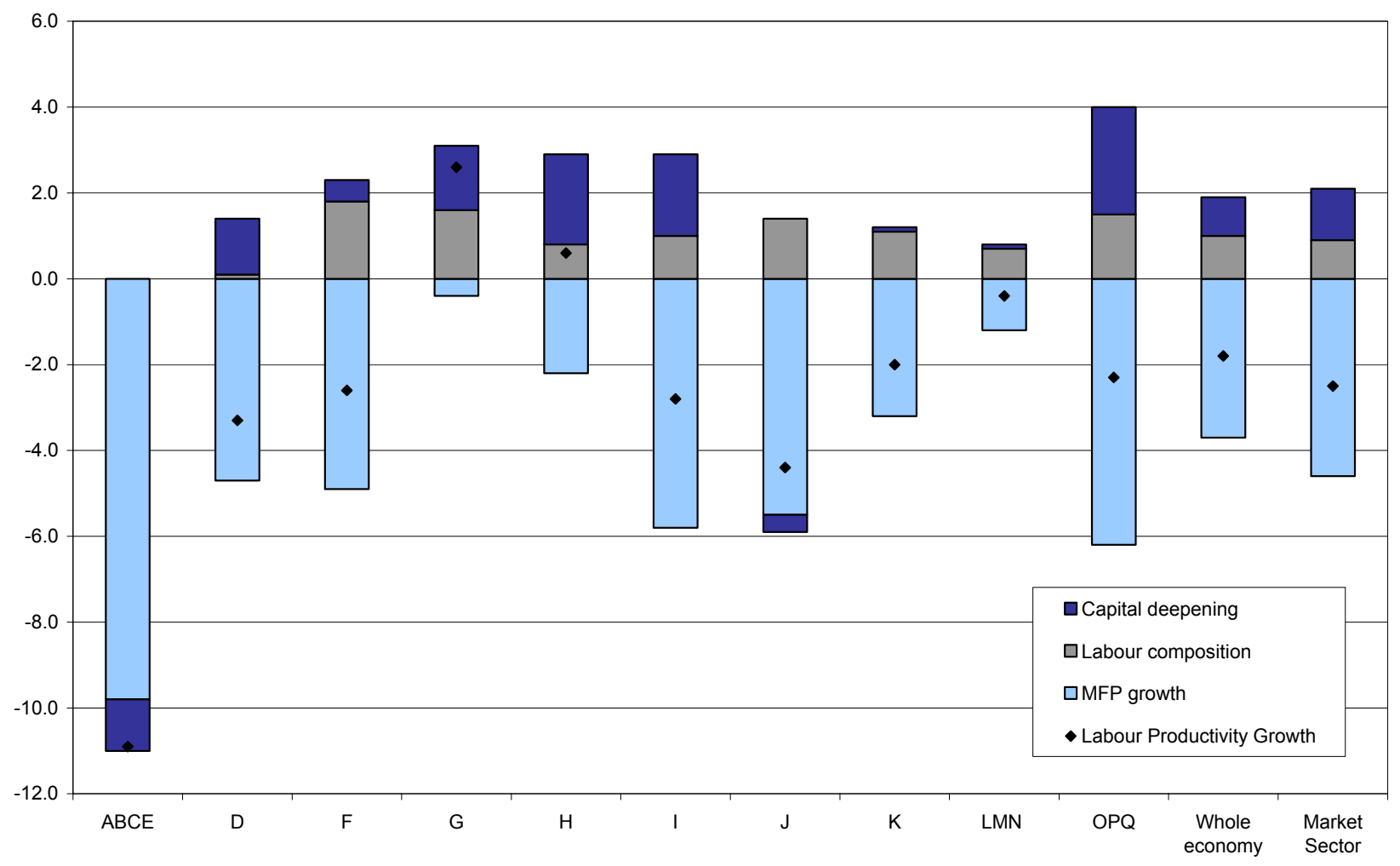

Source: Office for National Statistics

\section{Revisions since previous release}

Revisions to the MFP results since Long and Franklin (2010) arise from revisions to the component series and can be categorised into three broad groups:

- revisions to the National Accounts data in Blue Book 2010

- revisions to QALI and labour input estimates

- revisions to VICS estimates

There were few changes in the structure of the National Accounts in Blue Book 2010, although GVA was revised due to the updating of the reference year from 2005 to 2006 . This impacts on the entire time series but there are no significant revisions to growth rates prior to 2006. 
Revisions to the QALI and labour input series are driven by revisions to National Accounts Compensation of Employees data and annual benchmarking of the LFS micro data.

Revisions to the VICS estimates arise primarily from balancing revisions to the constant price investment series, new data on computer hardware investment and a new tax adjustment factor methodology. These revisions are described in more detail in Appleton and Wallis (2011).

To give an indication of the drivers of revisions to output growth, Figure 6 plots the average contributions at the whole economy level for the most recent and previous estimates. The data cover the period 1994 to 2008 , over which comparable data are available. Over this period, average output growth has been revised marginally downwards. Compared to the previous estimates, capital input has been revised upward by 0.11 percentage points, which feeds through into a downward revision of 0.12 percentage points to MFP.

\section{Figure 6 Contributions to whole economy annual average output} growth, 1994 to 2008: new and previous estimates

Percentage points

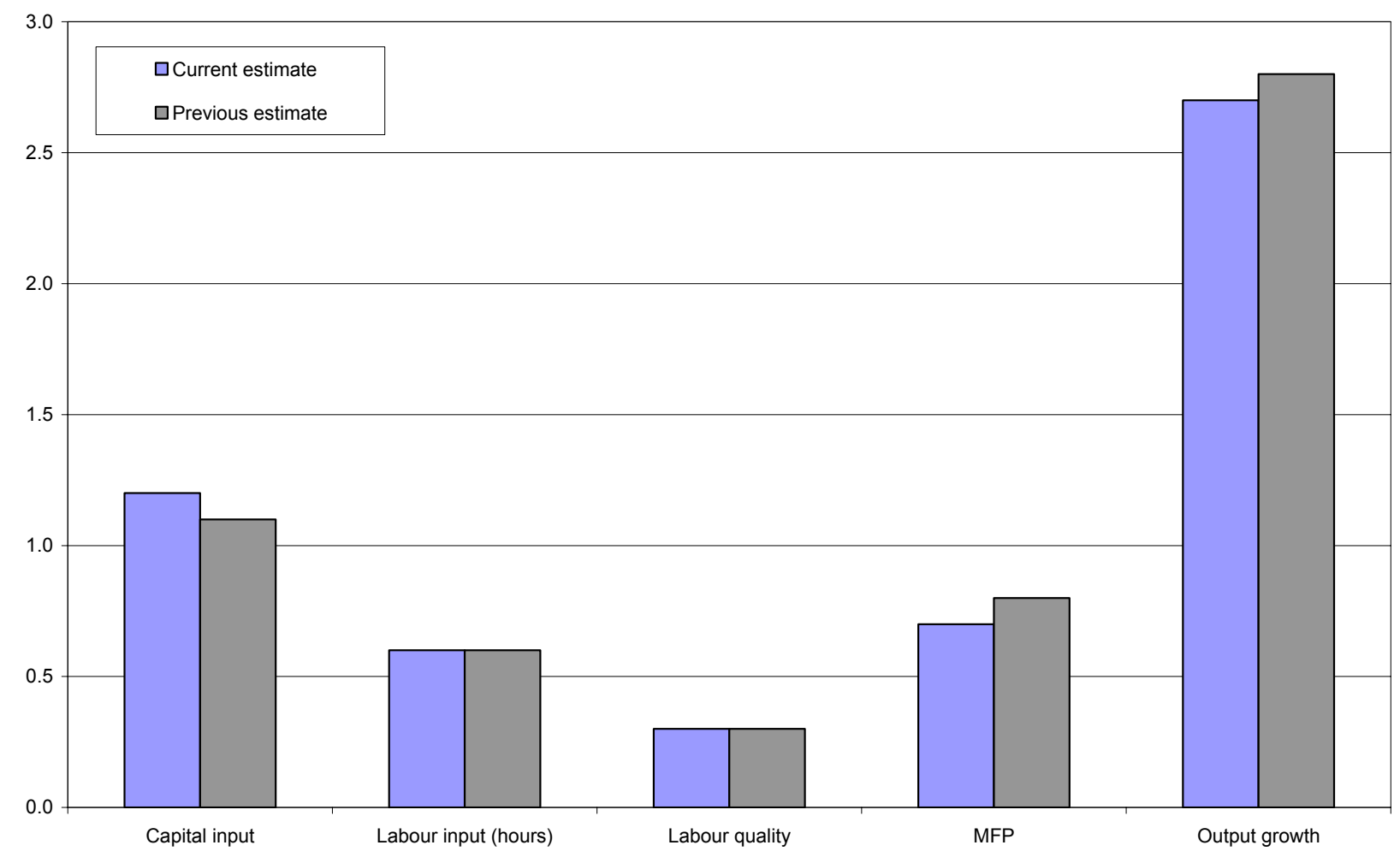

Source: Office for National Statistics 


\section{Conclusion}

Over the period 1995 to 2009 , MFP had a positive impact on growth of the whole economy and market sector; however its performance was mixed across individual industries. Its contribution in the market sector was greater than that of the whole economy due to the negative contribution of MFP to growth in the predominantly non-market industries LMN and OPQ. However, the contribution to growth due to labour composition was larger for the whole economy, owing to greater utilisation of highly skilled labour in LMN and OPQ.

Backcasting the data to 1970 highlighted that MFP and capital inputs have been the drivers of growth for the whole economy over the long run. In transport, storage and communications, MFP has accounted for 75 per cent of output growth, the largest contribution for any industry

Finally, MFP fell sharply over the recession, as did labour hours. However, the pro-cyclical nature of MFP suggests it is to be expected that it will increase again in the coming years, as the UK leaves recession behind

\section{Notes}

1. An alternative approach to growth accounting is to use a gross output measure and calculate the contributions to growth not only from capital and labour inputs but from intermediate inputs as well, Phelps (2010). An example of this approach is the EUKLEMS project (see www.euklems.net) which additionally apportions output growth to the intermediate inputs of energy, materials and services. Whilst this approach to growth accounting is conceptually preferred, its data requirements are much more onerous. In particular, constant price supply use tables, which are not currently published by the ONS, represent a barrier to adoption of this approach.

2. See http://www.statistics.gov.uk/cci/nugget.asp?id=133 for the latest labour productivity estimates.

3. The National Accounts define market sector activity as that which is undertaken at prices that are economically significant and where the output is disposed of or intended for sale through the market.

4. The EU KLEMS project, which ran from 2003 to 2008, created a database on measures of economic growth, productivity, employment creation, capital formation and technological change at the industry level for all European Union member states from 1970 onwards. The database's growth accounting variables and its level of industrial disaggregation allow backcasting of ONS series in a consistent manner. Further details available at: http://www.euklems.net/

5. See www.statistics.gov.uk/ukcemga for further information on this development.

6. A breakdown of Figure 3 into shorter time periods is provided in the Annex. 


\section{Acknowledgements}

The author wishes to thank Mark Franklin and John Appleton for their help in producing this article.

\section{Contact}

elmr@ons.gov.uk

\section{References}

Acheson J (2011) 'Quality-adjusted labour input: new quarterly estimates for 1993 to 2009 and annual estimates from 1970', Economic \& Labour Market Review, vol. 5, no. 4, pp. 22-46 and at http://www.statistics.gov.uk/CCl/article.asp?ID=2668

Appleton J and Wallis G (2011) 'Volume of capital services: estimates for 1950 to 2009'. Economic \& Labour Market Review, vol. 5, no. 5, pp. 46-66

Baumol W J (1967) 'Macroeconomics of Unbalanced Growth: The Anatomy of Urban Crisis', American Economic Review, vol. 57, no. 3, pp. 415-426

Long K, and Franklin M (2010) 'Multi-factor Productivity: Estimates for 1994 to 2008', Economic \& Labour Market Review, vol. 4, no. 9, pp. 67-72 and at www.statistics.gov.uk/CCl/article.asp?ID=2576

Phelps M (2010) 'Comparing different estimates of productivity produced by the Office for National Statistics', Economic \& Labour Market Review, vol. 4, no. 5, pp. 25-29 and at www.statistics.gov.uk/cci/article.asp?ID $=2413$

Solow R M (1957) 'Technical Change and the Aggregate Production Function', Review of Economics and Statistics, vol. 39, no. 3, pp. 312-320. 
Annex: Average growth rates for 1970 to 2009

\begin{tabular}{|c|c|c|c|c|}
\hline & $1970-79$ & $1980-89$ & $1990-99$ & 2000-09 \\
\hline \multicolumn{5}{|l|}{ GVA } \\
\hline$A B C E$ & -0.2 & 0.9 & 2.9 & -2.7 \\
\hline D & 0.6 & 1.0 & 0.7 & -1.2 \\
\hline $\mathrm{F}$ & -0.5 & 3.4 & 0.2 & 0.8 \\
\hline G & 0.4 & 3.0 & 1.7 & 2.1 \\
\hline $\mathrm{H}$ & 0.9 & 2.3 & 0.8 & 1.5 \\
\hline I & 2.6 & 2.9 & 5.9 & 2.5 \\
\hline J & 2.6 & 3.0 & 3.5 & 4.4 \\
\hline K & 3.8 & 4.6 & 3.9 & 3.3 \\
\hline LMN & 1.7 & 0.1 & 0.9 & 1.7 \\
\hline $\mathrm{OPQ}$ & 2.7 & 3.5 & 3.6 & 0.5 \\
\hline Whole Economy & 2.3 & 2.4 & 2.2 & 1.7 \\
\hline Market Sector & 1.9 & 2.7 & 2.5 & 1.7 \\
\hline \multicolumn{5}{|l|}{ MFP } \\
\hline$A B C E$ & -0.3 & 1.1 & 3.8 & -2.5 \\
\hline D & 1.3 & 3.1 & 1.3 & 1.6 \\
\hline $\mathrm{F}$ & -0.4 & 1.9 & 1.4 & -0.4 \\
\hline G & -1.5 & 1.8 & -0.2 & 1.1 \\
\hline $\mathrm{H}$ & -2.1 & -1.0 & -1.7 & -1.8 \\
\hline I & 2.2 & 3.5 & 4.4 & 0.4 \\
\hline $\mathrm{J}$ & -2.1 & -1.6 & 0.9 & 2.4 \\
\hline K & -0.8 & -1.4 & -1.5 & -0.7 \\
\hline LMN & -1.5 & -1.1 & -0.6 & -0.7 \\
\hline OPQ & -1.5 & -1.2 & 0.7 & -3.3 \\
\hline Whole Economy & 1.1 & 1.6 & 0.9 & 0.2 \\
\hline Market Sector & & & 0.7 & 0.4 \\
\hline \multicolumn{5}{|c|}{ Labour Composition } \\
\hline ABCE & 0.1 & -0.4 & -0.2 & 0.1 \\
\hline $\mathrm{D}$ & 0.1 & -0.1 & 0.5 & 0.6 \\
\hline $\mathrm{F}$ & 0.0 & 0.2 & 0.3 & 0.1 \\
\hline $\mathrm{G}$ & 0.2 & -0.3 & 0.4 & 0.5 \\
\hline $\mathrm{H}$ & 0.1 & -0.3 & -0.1 & 1.0 \\
\hline
\end{tabular}




\begin{tabular}{lcccc}
\hline & $\mathbf{1 9 7 0 - 7 9}$ & $\mathbf{1 9 8 0 - 8 9}$ & $\mathbf{1 9 9 0 - 9 9}$ & $\mathbf{2 0 0 0 - 0 9}$ \\
\hline $\mathrm{J}$ & 0.0 & -0.2 & 0.3 & 0.3 \\
$\mathrm{~J}$ & 0.5 & -0.1 & 0.8 & 1.2 \\
LMN & 1.2 & 0.9 & 0.4 & 0.4 \\
OPQ & 0.9 & 0.1 & 0.6 & 0.4 \\
Whole Economy & 1.1 & 1.0 & 0.5 & 0.5 \\
Market Sector & 0.4 & 0.0 & 0.4 & 0.4
\end{tabular}

\section{Labour input (hours)}

\begin{tabular}{|c|c|c|c|c|}
\hline ABCE & -1.4 & -0.8 & -1.2 & -0.1 \\
\hline D & -1.3 & -2.3 & -1.9 & -3.2 \\
\hline $\mathrm{F}$ & -0.4 & 1.2 & -1.8 & 0.5 \\
\hline G & 1.0 & 0.5 & 0.3 & -0.6 \\
\hline $\mathrm{H}$ & 0.8 & 2.1 & 1.3 & 0.7 \\
\hline I & -0.6 & -0.1 & -0.4 & -0.1 \\
\hline J & 2.3 & 2.8 & -0.1 & -0.2 \\
\hline K & 2.2 & 3.2 & 1.8 & 1.7 \\
\hline LMN & 1.7 & 0.5 & 0.2 & 1.4 \\
\hline OPQ & 1.4 & 1.7 & 0.1 & 1.0 \\
\hline Whole Economy & 0.0 & 0.1 & -0.2 & 0.2 \\
\hline Market Sector & & & 0.9 & 0.0 \\
\hline \multicolumn{5}{|l|}{ Capital input } \\
\hline ABCE & 1.4 & 0.9 & 0.4 & -0.2 \\
\hline $\mathrm{D}$ & 0.5 & 0.3 & 0.6 & -0.2 \\
\hline $\mathrm{F}$ & 0.2 & 0.1 & 0.3 & 0.6 \\
\hline G & 0.8 & 0.9 & 1.2 & 1.1 \\
\hline $\mathrm{H}$ & 2.0 & 1.5 & 1.3 & 1.6 \\
\hline I & 0.9 & -0.3 & 1.7 & 1.9 \\
\hline$J$ & 1.8 & 1.9 & 1.8 & 1.0 \\
\hline $\mathrm{K}$ & 1.2 & 1.9 & 3.1 & 1.9 \\
\hline LMN & 0.6 & 0.5 & 0.7 & 0.6 \\
\hline $\mathrm{OPQ}$ & 1.6 & 2.0 & 2.3 & 2.2 \\
\hline Whole Economy & 0.7 & 0.7 & 1.2 & 0.9 \\
\hline Market Sector & & & 1.8 & 1.0 \\
\hline
\end{tabular}

